\title{
ATRIBUTOS QUÍMICOS DO SOLO DECORRENTES DA APLICAÇÃO EM SUPERFÍCIE DE CALCÁRIO E GESSO EM SISTEMA PLANTIO DIRETO RECÉM-IMPLANTADO(1)
}

\author{
Rogério Peres Soratto ${ }^{(2)}$ \& Carlos Alexandre Costa Crusciol ${ }^{(3)}$
}

\begin{abstract}
RESUMO
Há interesse em implantar o sistema plantio direto em áreas anteriormente cultivadas no sistema convencional ou sob pastagem, corrigindo a acidez com calagem superficial após a implantação do sistema. Essa prática pode ser possível desde que não haja impedimento físico do solo ao crescimento radicular. Nesse sentido, o gesso é uma alternativa para diminuição da atividade do $\mathrm{Al}^{3+}$ e aumento da saturação por bases (V), principalmente $\mathrm{Ca}^{2+}$, nas camadas do subsolo, podendo ser utilizado como produto complementar ao calcário. Este trabalho objetivou avaliar as alterações dos atributos químicos do solo $\left(\mathrm{pH} \mathrm{CaCl}_{2}, \mathrm{H}+\mathrm{Al}, \mathrm{Al}^{3+}, \mathrm{Ca}^{2+}\right.$, $\mathrm{Mg}^{2+}, \mathrm{S}_{-} \mathrm{SO}_{4}{ }^{2-}, \mathrm{V}$ e teor de micronutrientes catiônicos) decorrentes da aplicação de calcário e de gesso agrícola em superfície em sistema plantio direto recémimplantado em região de inverno seco. O experimento foi conduzido em um Latossolo Vermelho distroférrico de Botucatu (SP). O delineamento experimental foi em blocos casualizados com parcelas subdivididas e quatro repetições. As parcelas foram constituídas por quatro doses de calcário dolomítico com PRNT de $71,2 \%\left(0,1.100,2.700\right.$ e $\left.4.300 \mathrm{~kg} \mathrm{ha}^{-1}\right)$, visando elevar a saturação por bases a 50,70 e $90 \%$, respectivamente. As subparcelas foram constituídas pelas doses de gesso agrícola de 0 e $2.100 \mathrm{~kg} \mathrm{ha}^{-1}$. Amostras de terra foram coletadas nas profundidades de $0-0,05,0,05-0,10,0,10-0,20,0,20-0,40,0,40-0,60$ e $0-0,20 \mathrm{~m}$, aos três, seis, 12 e 18 meses da aplicação dos produtos. A aplicação superficial de calcário diminuiu a acidez e elevou os teores de $\mathrm{Ca}$ e Mg trocável, principalmente nas camadas superficiais do solo. A aplicação de gesso agrícola aumentou os teores de Ca trocável e $\mathrm{S}_{-} \mathrm{SO}_{4}{ }^{2-}$, e diminuiu os teores de Al no solo, contribuindo para que os efeitos da calagem superficial nas características químicas do solo alcançassem, de forma mais rápida, as camadas do subsolo. Os valores de saturação por bases obtidos na
\end{abstract}

\footnotetext{
(1) Parte da Tese de Doutorado do primeiro autor apresentada à Faculdade de Ciências Agronômicas, Universidade Estadual Paulista - FCA/UNESP. Recebido para publicação em março de 2007 e aprovado em novembro de 2007.

(2) Professor Assistente Doutor do Departamento de Produção Vegetal, Faculdade de Ciências Agronômicas, Universidade Estadual Paulista - FCA/UNESP. Campus de Botucatu, Caixa Postal 237, CEP 18603-970 Botucatu (SP). E-mail: soratto@fca.unesp.br

(3) Professor Adjunto do Departamento de Produção Vegetal, FCA/UNESP. Bolsista do CNPq. E-mail: crusciol@fca.unesp.br
} 
profundidade de $0-0,20 \mathrm{~m}$ com a calagem foram menores do que os estimados pelo método da elevação da saturação por bases, principalmente nas maiores doses, mesmo com a aplicação de gesso agrícola. A calagem em superfície não alterou os teores de micronutrientes na camada de $0-0,20 \mathrm{~m}$ de profundidade.

Termos de indexação: acidez do solo, fertilidade do solo, calagem, lixiviação de ions.

\title{
SUMMARY: CHEMICAL SOIL ATTRIBUTES AS AFFECTED BY LIME AND PHOSPHOGYPSUM SURFACE APPLICATION IN A RECENTLY ESTABLISHED NO-TILLAGE SYSTEM
}

\begin{abstract}
There is interest to establish the no-tillage system in areas cultivated previously with conventional tillage or pasture, with surface liming after system establishment. This practice is possible provided that there are no physical obstacles for root growth. Phosphogypsum is an alternative to decrease $A l^{3+}$ and increase base saturation (BS), mainly $\mathrm{Ca}^{2+}$, in the subsoil, and can be used complementary to liming. The objective of this study was to evaluate the changes in chemical soil attributes ( $\mathrm{pH} \mathrm{CaCl}, \mathrm{H}+\mathrm{Al}, \mathrm{Al}^{3+}, \mathrm{Ca}^{2+}, \mathrm{Mg}^{2+}$, $\mathrm{S}_{-} \mathrm{SO}_{4}^{2-}, \mathrm{BS}$, and content of cationic micronutrients) as affected by lime and phosphogypsum surface application in a recently established no-tillage system in dry-winter region. The experiment was carried out on a dystroferric Haplorthox, in Botucatu County, São Paulo State, Brazil. A randomized complete block design, in split-plot scheme and four replications, was used. The plots consisted of four dolomitic limestone rates $(0 ; 1,100$; 2,700; and 4,300 $\mathrm{kg} \mathrm{ha}^{-1}$ ), intended to reach a $B S$ to 50, 70 and $90 \%$, respectively. The subplots were represented by the absence or presence of phosphogypsum application $\left(2,100 \mathrm{~kg} \mathrm{ha}^{-1}\right)$. Soil samples were collected 3, 6, 12, and 18 months after lime and phosphogypsum application, at depths of $0-0.05,0.05-0.10,0.10-0.20,0.20-0.40,0.40$ 0.60 , and $0-0.20 \mathrm{~m}$. Lime surface application reduced soil acidity and increased exchangeable Ca and Mg contents, mainly in the top soil layers. Phosphogypsum application promoted increasing exchangeable $\mathrm{Ca}$ and $\mathrm{S}_{-} \mathrm{SO}_{4}{ }^{2-}$ contents, and decreased exchangeable Al in the soil, favoring the effects of surface liming that influenced the subsoil layers more rapidly. Base saturation values obtained at a depth of $0-0.20 \mathrm{~m}$ with liming were lower than those estimated by BS method, mainly at the highest levels, even with phosphogypsum application. Surface liming did not influence micronutrient contents in the 0-0.20 m layer.
\end{abstract}

Index terms: soil acidity, soil fertility, liming, ion leaching.

\section{INTRODUÇÃO}

A calagem é a prática mais comumente utilizada para neutralizar a acidez, aumentar a disponibilidade de nutrientes, diminuir o teor de elementos tóxicos, melhorar o ambiente radicular e restaurar a capacidade produtiva dos solos (Caires et al., 2005). O calcário, quando misturado ao solo e com água, dissolve-se e o carbonato de cálcio dissocia-se (Quaggio, 2000). Os produtos da dissolução do calcário reagem com os colóides do solo e, nessa reação, elevam o pH, os teores de $\mathrm{Ca}$ e $\mathrm{Mg}$ e a saturação por bases, e diminuem o $\mathrm{Al}$ e o Mn trocáveis no solo. Segundo Raij et al. (1996), a reação do calcário é restrita a uma pequena distância do local da aplicação, assim o benefício máximo é obtido com a aplicação antecipada, distribuição uniforme e a incorporação profunda.
No entanto, a incorporação do calcário ao solo, mediante revolvimento com arações e gradagens, altera as características físicas do solo, diminuindo a porosidade, a distribuição de tamanho e a estabilidade dos agregados, além de destruir os canais resultantes do crescimento radicular e da atividade biológica, o que prejudica a infiltração de água, aumentando o escorrimento superficial e facilitando a erosão (Hermani et al., 1999; Stone \& Silveira, 1999). Amado et al. (2001) observaram redução de, aproximadamente, $25 \%$ do estoque de matéria orgânica de um Argissolo Amarelo (150 $\mathrm{g} \mathrm{kg}^{-1}$ de argila) em campo nativo, com apenas uma aração e duas gradagens para incorporação de calcário e fertilizantes.

O sistema plantio direto é uma das melhores alternativas para a manutenção da sustentabilidade dos recursos naturais na utilização agrícola dos solos 
tropicais e subtropicais. Nesse contexto, tem aumentado o interesse pela busca de alternativas para o estabelecimento de culturas no sistema plantio direto em áreas anteriormente cultivadas no sistema convencional de preparo do solo ou sob pastagens, sem a incorporação prévia do calcário, realizando-se a calagem superficialmente, o que pode ser feito desde que não haja impedimento físico ao crescimento radicular. As vantagens desse procedimento estão relacionadas, principalmente, com maior controle da erosão e com a economia nas operações de preparo do solo e incorporação de corretivos (Caires et al., 2003).

No sistema plantio direto, diversos trabalhos têm demonstrado que o efeito da calagem aplicada na superfície para a correção das camadas subsuperficiais varia com a dose e granulometria do produto; forma de aplicação; tipo de solo; condições climáticas, especialmente regime hídrico; sistema de cultivo; e tempo decorrido da aplicação (Oliveria \& Pavan, 1996; Caires et al., 1999, 2000, 2003, 2005; Rheinheimer et al., 2000; Mello et al., 2003; Alleoni et al., 2005), o que torna a eficiência dessa prática controvertida, particularmente na correção da acidez do subsolo.

A diminuição do $\mathrm{Al}$ trocável e o aumento do $\mathrm{pH}$ do solo, até $0,40 \mathrm{~m}$ de profundidade, 32 meses após a aplicação de calcário na superfície, foram constatados por Oliveira \& Pavan (1996) em Latossolo Vermelho, na região de Ponta Grossa-PR, em sistema plantio direto estabelecido há cerca de um ano. Em solo semelhante e na mesma região, Caires et al. (1999) observaram aumento nos valores de $\mathrm{pH}$ e nos teores de $\mathrm{Ca}$ e $\mathrm{Mg}$, além da diminuição do Al trocável até a profundidade de 0,40 m, 18 meses após a aplicação de calcário em superfície, em um solo sob plantio direto há 15 anos. Lima (2004), em um Nitossolo Vermelho distrófico textura argilosa, na região de Botucatu-SP, verificou aumento do $\mathrm{pH}$ e da saturação por bases até a profundidade de $0,40 \mathrm{~m}$, cinco meses após a aplicação do calcário na implantação do sistema plantio direto.

Por outro lado, também na região de Botucatu, em um Latossolo Vermelho distroférrico, Barizon (2001) verificou efeito da calagem superficial na diminuição da acidez potencial e elevação do $\mathrm{pH}$ apenas na camada superficial (0-0,05 m), 10 meses após a aplicação do corretivo, na implantação do sistema plantio direto. Além disso, em outras regiões com regimes hídricos distintos, há relatos de que o efeito da aplicação superficial de calcário, restringiu-se às camadas de 0-0,10 m, 12 meses (Caires et al., 1998) e 30 meses (Alleoni et al., 2005), e 0-0,05 m, 34 meses após a aplicação de corretivo na superfície (Pöttker \& Ben, 1998), no sistema plantio direto consolidado, evidenciando que ainda há muitas dúvidas quanto à eficiência dessa prática.

Considerando que a calagem sem incorporação pode ter sua ação limitada às camadas superficiais, principalmente nos primeiros anos de cultivo, a aplicação de gesso agrícola em superfície pode ser uma alternativa para aumentar a saturação por bases na subsuperfície e reduzir o efeito tóxico do $\mathrm{Al}^{3+}$, melhorando assim o ambiente radicular para o crescimento das plantas. A combinação de calcário com gesso agrícola pode compensar o efeito reduzido do calcário no subsolo, nos primeiros anos de cultivo, sem necessidade de incorporação prévia (Caires et al., 2003). O efeito do gesso agrícola para diminuir o problema de teor tóxico de $\mathrm{Al}$ e do baixo teor de $\mathrm{Ca}$, no subsolo, é decorrente da sua maior solubilidade em relação ao calcário e da reatividade do ânion acompanhante. Na dissolução do calcário $\left(\mathrm{CaCO}_{3}\right.$ ou $\mathrm{MgCO}_{3}$ ), o $\mathrm{CO}_{3}{ }^{2-}$ se decompõe facilmente em condições de acidez, por ser menos estável que o $\mathrm{SO}_{4}{ }^{2-}$. Assim o deslocamento do Ca no perfil do solo é muito maior quando a fonte é o gesso $\left(\mathrm{CaSO}_{4} \cdot 2 \mathrm{H}_{2} \mathrm{O}\right)$, comparado com o calcário (Dal Bó et al., 1986). O gesso agrícola aplicado na superfície do solo movimenta-se ao longo do perfil sob a influência da percolação de água (Caires et al., 1999). Como conseqüência, obtêm-se aumento no suprimento de Ca e diminuição da toxidez de $\mathrm{Al}$ no subsolo (Caires et al., 1999, 2003).

A maioria dos trabalhos com aplicação de calcário e gesso em superfície foi realizada em condições de sistema plantio direto consolidado e em regiões sem limitação hídrica (Pöttker \& Ben, 1998; Caires et al., 1998, 1999, 2000, 2003, 2004, 2005), o que pode ter interferido no efeito da calagem superficial na correção da acidez do subsolo (Myiazawa et al., 2002; Alleoni et al., 2005). Contudo, pouco se conhece sobre os efeitos, nos atributos químicos do solo, da aplicação de calcário e gesso em superfície num sistema plantio direto recém-implantado e em região com limitação hídrica durante alguns meses do ano.

Este trabalho objetivou avaliar as alterações dos atributos químicos do solo decorrentes da aplicação de calcário e gesso agrícola em superfície, em sistema plantio direto recém-implantado, em região de inverno seco.

\section{MATERIAL E MÉTODOS}

O trabalho foi realizado na Fazenda Experimental Lageado, pertencente à Faculdade de Ciências Agronômicas - UNESP, município de Botucatu, SP, localizada a $48^{\circ} 23^{\prime} \mathrm{W}$ e $22^{\circ} 51^{\prime}$ ' $\mathrm{S}$, com altitude de $765 \mathrm{~m}$. O solo local é um Latossolo Vermelho distroférrico (Embrapa, 2006), o qual foi cultivado no sistema convencional por oito anos, permanecendo dois anos em pousio. Em fevereiro de 2001, foi cultivada soja (safrinha) mediante preparo de solo convencional (uma aração e duas gradagens). Em outubro de 2001, após subsolagem semeouse guandu (Cajanus cajan (L.) Millsp.), sem preparo do solo, que foi manejado com triturador de palha em 2/10/ 2002. Assim, o experimento foi implantado em uma área onde o sistema plantio direto havia sido implantado há aproximadamente um ano. O clima édo tipo Cwa, segundo a classificação de Köppen, caracterizado como tropical de altitude, com inverno seco e verão quente e chuvoso. 
O experimento foi conduzido no período de outubro de 2002 a abril de 2004. As amostras para caracterizações químicas (Raij et al., 2001) e granulométricas (Embrapa, 1997) foram coletadas em agosto de 2002. O resultado das análises químicas da camada de 0-0,20 m são os seguintes: matéria orgânica de 20,9 $\mathrm{g} \mathrm{dm}^{-3} ; \mathrm{pH}\left(0,01 \mathrm{~mol} \mathrm{~L}^{-1} \mathrm{CaCl}_{2}\right)$ de 4,2; P (resina) de 9,2 $\mathrm{mg} \mathrm{dm}^{-3} ; \mathrm{K}, \mathrm{Ca}, \mathrm{Mg}, \mathrm{H}+\mathrm{Al} \mathrm{e}$ CTC de 1,2, 14,0,5,0,36,8 e 58,0 $\mathrm{mmol}_{\mathrm{c}} \mathrm{dm}^{-3}$, respectivamente; $\mathrm{e} \mathrm{V}=37 \%$. Os teores de areia, silte e argila da camada de $0-0,20$ e $0,20-0,40 \mathrm{~m}$ foram, respectivamente, de 545, 108 e $347 \mathrm{~g} \mathrm{~kg}^{-1}$, e $513,127 \mathrm{e}$ $360 \mathrm{~g} \mathrm{~kg}^{-1}$.

Os tratamentos consistiram da combinação de quatro doses de calcário dolomítico e duas doses de gesso agrícola aplicadas na superfície, sem incorporação, constituindo um fatorial $4 \times 2$. Os tratamentos foram distribuídos em blocos ao acaso com quatro repetições. Nas parcelas $(18,0$ x 5,4 m) foram adicionadas doses de calcário dolomítico: 0 , $1.100,2.700$ e $4.300 \mathrm{~kg} \mathrm{ha}^{-1}$, visando elevar a saturação por bases para 50,70 e $90 \%$, respectivamente. Nas subparcelas $(9,0$ x 5,4 m) foram adicionados os tratamentos sem e com gesso agrícola na dose de $2.100 \mathrm{~kg} \mathrm{ha}^{-1}$. A dose de gesso, foi calculada de acordo com recomendação de Raij et al. (1996), ou seja, a dose gesso, em kg ha-1, foi igual a seis vezes o teor de argila, em $\mathrm{g} \mathrm{kg}^{-1}$, na camada de $0,20-0,40 \mathrm{~m}$ de profundidade.

A composição química do calcário foi de $23,3 \%$ de $\mathrm{CaO}, 17,5 \%$ de $\mathrm{MgO}$ e $71,2 \%$ de PRNT, e do gesso agrícola foi de $20 \%$ de Ca e $16 \%$ de $\mathrm{S}$.

O calcário foi aplicado a lanço sobre os restos culturais de guandu no dia 15/10/2002, nas parcelas, de acordo com as doses estabelecidas. No dia 16/10/ 2002, realizou-se a aplicação de gesso agrícola em metade de todas as parcelas, constituindo as subparcelas.

A área foi cultivada com a sucessão arroz/aveiapreta/feijão/aveia-preta, utilizando como adubação básica $300 \mathrm{~kg}$ ha-1 da fórmula $\left(\mathrm{N}-\mathrm{P}_{2} \mathrm{O}_{5}-\mathrm{K}_{2} \mathrm{O}\right) 8-28$ $16+4,5 \%$ de $\mathrm{S}+0,5 \%$ de $\mathrm{Zn}, 200 \mathrm{~kg} \mathrm{ha}^{-1}$ da fórmula $10-20-10,300 \mathrm{~kg} \mathrm{ha}^{-1}$ das fórmulas 8-28-16 + 4,5\% de S + 0,5 \% de Zn e $200 \mathrm{~kg} \mathrm{ha}^{-1}$ de $4-20-10+7,0 \%$ de $\mathrm{S}$, respectivamente. Nas culturas do arroz e do feijão, também foram realizadas adubações nitrogenadas de cobertura, com $50 \mathrm{~kg} \mathrm{ha}^{-1}$ de $\mathrm{N}$, utilizando como fonte a uréia, e $110 \mathrm{~kg} \mathrm{ha}^{-1}$ de N, utilizando como fonte o nitrato de amônio, respectivamente.

As amostras foram coletadas aos três, seis, 12 e 18 meses após a aplicação do calcário e do gesso, nas camadas de $0-0,05,0,05-0,10,0,10-0,20,0,20-0,40$, 0,40-0,60 e 0-0,20 m de profundidade, na área útil de cada subparcela. Cada amostra foi composta por sete amostras simples nas três camadas mais superficiais ou quatro amostras simples nas duas camadas mais profundas, coletadas sempre na entrelinha da cultura da área, com a utilização de trado tipo sonda. A precipitação pluvial ocorrida desde a instalação do experimento até a realização de cada uma das amostragens foi de $636,5,1.170,4,1.407,9$ e $2.519,8 \mathrm{~mm}$, respectivamente.

Nas amostras foram determinados: $\mathrm{pH}$ em $\mathrm{CaCl}_{2}$ $0,01 \mathrm{~mol} \mathrm{~L}^{-1}$ (relação solo:solução 1:2,5), a acidez potencial $(\mathrm{H}+\mathrm{Al})$, os teores de $\mathrm{Ca}, \mathrm{Mg}$ e $\mathrm{K}$ no solo extraídos pela resina trocadora de íons segundo métodos descritos por Raij et al. (2001); com esses resultados foram calculados os valores de saturação por bases (V) mediante a relação entre o teor de bases trocáveis no solo (Ca, $\mathrm{Mg}$ e K) e a capacidade de troca de cátions (CTC) em porcentagem. O enxofre foi extraído com fosfato monocálcico, sendo a quantificação feita por turbidimetria, provocada por $\mathrm{BaSO}_{4}$ formado pela reação do $\mathrm{BaCl}_{2} \cdot 2 \mathrm{H}_{2} \mathrm{O}$ com o $\mathrm{SO}_{4}{ }^{2-}$, extraído das amostras de terra (Vitti, 1988). Nas amostras retiradas da camada de $0-0,20 \mathrm{~m}$, nos tratamentos que receberam apenas doses de calcário, foram determinados os teores de $\mathrm{Cu}, \mathrm{Fe}, \mathrm{Mn}$ e $\mathrm{Zn}$ extraídos por DTPA em $\mathrm{pH}$ 7,3, segundo metodologia descrita por Raij et al. (2001).

Dentro da mesma profundidade, os dados foram submetidos à análise de variância. As médias dos tratamentos de calcário foram ajustadas a equações de regressão dentro de cada tratamento de gesso, independentemente do efeito da interação entre os fatores. As médias dos tratamentos de gesso agrícola foram comparadas pelo teste t (Quadro 1). Como os teores de micronutrientes foram avaliados apenas nos tratamentos sem aplicação de gesso, os dados foram submetidos a análise de regressão.

\section{RESULTADOS E DISCUSSÃO}

$\mathrm{Na}$ amostragem realizada aos três meses após a aplicação, verificou-se que a calagem, na ausência de gesso, promoveu aumento nos valores de $\mathrm{pH} \mathrm{CaCl}_{2}$ na camada $0-0,05 \mathrm{~m}$ de profundidade (Quadro 1 e Figura 1). Os efeitos da calagem sobre os valores de $\mathrm{pH}$ foram observados até a camada de $0,05-0,10 \mathrm{~m}$ aos seis meses após a aplicação, até a camada de $0,20-0,40 \mathrm{~m}$ aos 12 meses, e permaneceram até 0,10 $0,20 \mathrm{~m}$ de profundidade na amostragem realizada aos 18 meses.

O efeito da calagem em profundidade pode ter ocorrido devido ao deslocamento mecânico de partículas finas de calcário, através de canais formados por raízes mortas (Oliveira \& Pavan, 1996), de planos de fraqueza (Amaral et al., 2004), ou de galerias de organismos do solo e de macrocanais biológicos (Rheinheimer et al., 2000), os quais foram mantidos intactos pelo não revolvimento do solo. No entanto, devido ao fato do sistema plantio direto ter sido recentemente implantado em área anteriormente cultivada no sistema convencional de preparo do solo, provavelmente a maior parte do efeito da calagem em profundidade pode ser atribuída à movimentação de 
Quadro 1. Resumo da análise da variância para os atributos químicos do solo nas camadas de 0-0,05, 0,05-0,10, 0,10-0,20, 0,20-0,40 e 0,40-0,60 m de profundidade, aos três, seis, 12 e 18 meses após a aplicação de calcário e gesso em superfície

\begin{tabular}{|c|c|c|c|c|c|c|c|c|c|c|c|c|c|c|c|c|c|}
\hline \multirow{2}{*}{ Prof. } & \multirow{2}{*}{$\begin{array}{l}\text { Fonte de } \\
\text { variação }\end{array}$} & \multicolumn{4}{|c|}{$\mathrm{pH}\left(\mathrm{CaCl}_{2}\right)$} & \multicolumn{4}{|c|}{$\mathbf{H}+\mathbf{A l}$} & \multicolumn{4}{|c|}{$\mathrm{Al}^{3+}$} & \multicolumn{4}{|c|}{$\mathrm{S}_{-} \mathrm{SO}_{4}{ }^{2-}$} \\
\hline & & 3 & 6 & 12 & 18 & 3 & 6 & 12 & 18 & 3 & 6 & 12 & 18 & 3 & 6 & 12 & 18 \\
\hline \multirow{5}{*}{$\begin{array}{c}\mathrm{m} \\
0-0,05\end{array}$} & & & & & & & & & & & & & & & & & \\
\hline & $\mathrm{C}(\mathrm{SG})^{(1)}$ & $\mathrm{L}^{*(2)}$ & $\mathrm{L}^{* *}$ & $\mathrm{~L}^{* *}$ & $\mathrm{~L}^{* *}$ & $\mathrm{~L}^{0}$ & $\mathrm{~L}^{* *}$ & $\mathrm{~L}^{* *}$ & $\mathrm{~L}^{* *}$ & $\mathrm{~ns}$ & $\mathrm{~L}^{* *}$ & $\mathrm{~L}^{* *}$ & $\mathrm{~L}^{* *}$ & $\mathrm{~L}^{*}$ & $\mathrm{~ns}$ & $\mathrm{~ns}$ & $\mathrm{~ns}$ \\
\hline & $\mathrm{C}(\mathrm{CG})$ & $\mathrm{L}^{\circ}$ & $\mathrm{L}^{* *}$ & $\mathrm{~L}^{* *}$ & $\mathrm{~L}^{* *}$ & $\mathrm{~L}^{\circ}$ & $\mathrm{L}^{* *}$ & $\mathrm{~L}^{*}$ & $\mathrm{~L}^{* *}$ & $\mathrm{~ns}$ & $\mathrm{~L}^{* *}$ & $\mathrm{~L}^{*}$ & $\mathrm{~L}^{* *}$ & $\mathrm{Q}^{* *}$ & $\mathrm{~L}^{*}$ & $\mathrm{~ns}$ & ns \\
\hline & G & $\mathrm{ns}$ & $\mathrm{ns}$ & $\mathrm{ns}$ & * & $\mathrm{ns}$ & $\mathrm{ns}$ & $\mathrm{ns}$ & $\mathrm{ns}$ & $\mathrm{ns}$ & $* *$ & * & $\mathrm{ns}$ & $* *$ & $* *$ & $* *$ & $\mathrm{~ns}$ \\
\hline & $\mathrm{C} \times \mathrm{G}$ & $\mathrm{ns}$ & $\mathrm{ns}$ & $\mathrm{ns}$ & $\mathrm{ns}$ & $\mathrm{ns}$ & $\mathrm{ns}$ & $\mathrm{ns}$ & $\mathrm{ns}$ & $\mathrm{ns}$ & $* *$ & * & $\mathrm{ns}$ & * & $* *$ & $\mathrm{~ns}$ & $\mathrm{~ns}$ \\
\hline \multirow[t]{4}{*}{$0,05-0,10$} & C (SG) & $\mathrm{ns}$ & $\mathrm{L}^{*}$ & $\mathrm{~L}^{*}$ & $\mathrm{~L}^{* *}$ & ns & $\mathrm{L}^{0}$ & $\mathrm{~L}^{*}$ & $\mathrm{~L}^{*}$ & $\mathrm{~ns}$ & $\mathrm{~L}^{* *}$ & $\mathrm{~L}^{* *}$ & $\mathrm{~ns}$ & $\mathrm{~ns}$ & $\mathrm{~ns}$ & $\mathrm{~ns}$ & $\mathrm{~ns}$ \\
\hline & $\mathrm{C}(\mathrm{CG})$ & $\mathrm{L}^{\circ}$ & $\mathrm{L}^{* *}$ & $\mathrm{~ns}$ & $\mathrm{~L}^{* *}$ & $\mathrm{~ns}$ & $\mathrm{~L}^{\circ}$ & $\mathrm{ns}$ & ns & $\mathrm{ns}$ & $\mathrm{L}^{* *}$ & $\mathrm{~ns}$ & $\mathrm{~L}^{\circ}$ & $\mathrm{L}^{* *}$ & ns & $\mathrm{ns}$ & $\mathrm{ns}$ \\
\hline & G & $\mathrm{ns}$ & ns & ns & $\mathrm{ns}$ & $\mathrm{ns}$ & $\mathrm{ns}$ & ns & ns & $\mathrm{ns}$ & $*$ & $\mathrm{~ns}$ & $*$ & $* *$ & $\mathrm{~ns}$ & $*$ & $\mathrm{~ns}$ \\
\hline & $\mathrm{C} \times \mathrm{G}$ & $\mathrm{ns}$ & $\mathrm{ns}$ & $*$ & $\mathrm{~ns}$ & $\mathrm{~ns}$ & $\mathrm{~ns}$ & $*$ & $*$ & $\mathrm{~ns}$ & $\mathrm{~ns}$ & $*$ & $\mathrm{~ns}$ & $* *$ & $\mathrm{~ns}$ & $\mathrm{~ns}$ & $\mathrm{~ns}$ \\
\hline \multirow[t]{4}{*}{$0,10-0,20$} & C (SG) & $\mathrm{ns}$ & $\mathrm{ns}$ & $\mathrm{L}^{* *}$ & $\mathrm{~L}^{0}$ & $\mathrm{~ns}$ & $\mathrm{~ns}$ & $\mathrm{~L}^{* *}$ & $\mathrm{~ns}$ & $\mathrm{~ns}$ & $\mathrm{~L}^{* *}$ & $\mathrm{~L}^{* *}$ & $\mathrm{~ns}$ & $\mathrm{~ns}$ & $\mathrm{~ns}$ & $\mathrm{~ns}$ & ns \\
\hline & $\mathrm{C}(\mathrm{CG})$ & ns & $\mathrm{L}^{*}$ & $\mathrm{~ns}$ & $\mathrm{~ns}$ & ns & $\mathrm{ns}$ & $\mathrm{L}^{*}$ & $\mathrm{~ns}$ & ns & $\mathrm{ns}$ & $\mathrm{ns}$ & $\mathrm{ns}$ & $\mathrm{L}^{*}$ & ns & $\mathrm{ns}$ & $\mathrm{L}^{*}$ \\
\hline & G & $\mathrm{ns}$ & ns & ns & $\mathrm{ns}$ & $\mathrm{ns}$ & $\mathrm{ns}$ & $*$ & ns & ns & ns & ns & $\mathrm{ns}$ & $* *$ & $* *$ & $* *$ & $\mathrm{~ns}$ \\
\hline & $\mathrm{C} \times \mathrm{G}$ & $\mathrm{ns}$ & $*$ & $\mathrm{~ns}$ & $\mathrm{~ns}$ & $\mathrm{~ns}$ & $\mathrm{~ns}$ & * & ns & $\mathrm{ns}$ & ns & $*$ & ns & $\mathrm{ns}$ & $\mathrm{ns}$ & ns & $*$ \\
\hline \multirow[t]{4}{*}{$0,20-0,40$} & C (SG) & $\mathrm{ns}$ & ns & $\mathrm{L}^{*}$ & $\mathrm{~ns}$ & ns & $\mathrm{ns}$ & ns & $\mathrm{ns}$ & $\mathrm{L}^{* *}$ & $\mathrm{~ns}$ & $\mathrm{~L}^{* *}$ & $\mathrm{~ns}$ & $\mathrm{~ns}$ & ns & $\mathrm{ns}$ & $\mathrm{ns}$ \\
\hline & C (CG) & $\mathrm{ns}$ & ns & $\mathrm{L}^{* *}$ & $\mathrm{~ns}$ & ns & $\mathrm{ns}$ & ns & $\mathrm{ns}$ & $\mathrm{L}^{* *}$ & ns & $Q^{*}$ & $\mathrm{~ns}$ & $\mathrm{~L}^{* *}$ & ns & $\mathrm{ns}$ & ns \\
\hline & G & ns & ns & ns & $\mathrm{ns}$ & $\mathrm{ns}$ & $\mathrm{ns}$ & ns & ns & $\mathrm{ns}$ & ns & ns & $\mathrm{ns}$ & $* *$ & $* *$ & $* *$ & $* *$ \\
\hline & $\mathrm{C} \times \mathrm{G}$ & $\mathrm{ns}$ & ns & ns & $\mathrm{ns}$ & $\mathrm{ns}$ & $\mathrm{ns}$ & ns & ns & $\mathrm{ns}$ & * & $*$ & $\mathrm{~ns}$ & $* *$ & $\mathrm{~ns}$ & $\mathrm{~ns}$ & ns \\
\hline \multirow[t]{6}{*}{$0,40-0,60$} & C (SG) & $\mathrm{ns}$ & $\mathrm{ns}$ & $\mathrm{ns}$ & $\mathrm{ns}$ & $\mathrm{ns}$ & $\mathrm{ns}$ & $\mathrm{ns}$ & $\mathrm{ns}$ & $\mathrm{ns}$ & $\mathrm{ns}$ & $\mathrm{L}^{\circ}$ & $\mathrm{L}^{* *}$ & $\mathrm{~ns}$ & ns & ns & ns \\
\hline & C (CG) & $\mathrm{ns}$ & $\mathrm{ns}$ & $\mathrm{ns}$ & $\mathrm{ns}$ & ns & $\mathrm{ns}$ & ns & $\mathrm{ns}$ & $\mathrm{ns}$ & $\mathrm{ns}$ & $\mathrm{Q}^{*}$ & $\mathrm{~ns}$ & ns & ns & $\mathrm{ns}$ & ns \\
\hline & G & ns & ns & ns & $\mathrm{ns}$ & $\mathrm{ns}$ & ns & ns & $* *$ & ns & ns & ns & $\mathrm{ns}$ & $* *$ & $* *$ & $* *$ & $* *$ \\
\hline & $\mathrm{C} \times \mathrm{G}$ & $\mathrm{ns}$ & ns & $\mathrm{ns}$ & $\mathrm{ns}$ & $\mathrm{ns}$ & $\mathrm{ns}$ & ns & $\mathrm{ns}$ & $\mathrm{ns}$ & $\mathrm{ns}$ & * & $\mathrm{ns}$ & $\mathrm{ns}$ & $\mathrm{ns}$ & $\mathrm{ns}$ & $\mathrm{ns}$ \\
\hline & & \multicolumn{6}{|c|}{$\mathrm{Ca}^{2+}$} & \multicolumn{5}{|c|}{$\mathrm{Mg}^{2+}$} & \multicolumn{5}{|c|}{$\mathbf{V}$} \\
\hline & & 3 & & 6 & 12 & 18 & & 3 & 6 & 12 & & 18 & 3 & 6 & 12 & & 18 \\
\hline \multirow[t]{4}{*}{$0-0,05$} & C (SG) & $\mathrm{L}^{* *}$ & & $\mathrm{~L}^{*}$ & $\mathrm{~L}^{*}$ & $\mathrm{~L}^{* *}$ & & $\mathrm{~L}^{* *}$ & $\mathrm{~L}^{*}$ & $\mathrm{~L}^{* *}$ & & $\lambda^{* *}$ & $\mathrm{~L}^{* *}$ & $\mathrm{~L}^{* *}$ & $\mathrm{~L}^{*}$ & & $\mathrm{~L}^{* *}$ \\
\hline & $\mathrm{C}(\mathrm{CG})$ & $\mathrm{L}^{*}$ & & $\mathrm{~L}^{*}$ & $\mathrm{~L}^{* *}$ & $\mathrm{~L}^{* *}$ & & $\mathrm{Q}^{\circ}$ & $\mathrm{L}^{\circ}$ & $\mathrm{L}^{* *}$ & & $\lambda^{* *}$ & $\mathrm{~L}^{*}$ & $\mathrm{~L}^{* *}$ & $\mathrm{~L}^{* *}$ & & $\mathrm{~L}^{* *}$ \\
\hline & G & $* *$ & & ns & $* *$ & $* *$ & & $\mathrm{~ns}$ & ns & $\mathrm{ns}$ & & $\mathrm{ns}$ & $* *$ & $\mathrm{~ns}$ & $*$ & & $* *$ \\
\hline & $\mathrm{C} \times \mathrm{G}$ & * & & $\mathrm{ns}$ & ns & $\mathrm{ns}$ & & $\mathrm{ns}$ & $\mathrm{ns}$ & $\mathrm{ns}$ & & $\mathrm{ns}$ & * & ns & ns & & ns \\
\hline \multirow[t]{4}{*}{$0,05-0,10$} & C (SG) & $\mathrm{ns}$ & & $\mathrm{ns}$ & $\mathrm{ns}$ & $\mathrm{Q}^{*}$ & & $\mathrm{~ns}$ & $\mathrm{~ns}$ & $\mathrm{Q}^{* *}$ & & $\mathrm{~L}^{\circ}$ & $\mathrm{ns}$ & $\mathrm{ns}$ & $\mathrm{L}^{*}$ & & $\mathrm{~L}^{*}$ \\
\hline & $\mathrm{C}(\mathrm{CG})$ & ns & & $\mathrm{ns}$ & ns & $\mathrm{L}^{* *}$ & & $\mathrm{~ns}$ & $\mathrm{~ns}$ & $\mathrm{~L}^{*}$ & & $x^{* *}$ & ns & ns & ns & & $L^{*}$ \\
\hline & $\mathrm{G}$ & $*$ & & $*$ & $*$ & $\mathrm{~ns}$ & & $\mathrm{~ns}$ & $*$ & $* *$ & & $\mathrm{~ns}$ & $*$ & ns & $\mathrm{ns}$ & & $\mathrm{ns}$ \\
\hline & $\mathrm{C} \times \mathrm{G}$ & ns & & $\mathrm{ns}$ & ns & $*$ & & $\mathrm{~ns}$ & $\mathrm{~ns}$ & $\mathrm{~ns}$ & & * & ns & ns & $*$ & & ns \\
\hline \multirow[t]{4}{*}{$0,10-0,20$} & $\mathrm{C}$ (SG) & $\mathrm{L}^{*}$ & & $\mathrm{~ns}$ & $\mathrm{~L}^{*}$ & $\mathrm{Q}^{*}$ & & $\mathrm{~L}^{0}$ & $\mathrm{~L}^{*}$ & $\mathrm{~L}^{* *}$ & & $\mathrm{~ns}$ & $\mathrm{~ns}$ & ns & $\mathrm{L}^{* *}$ & & $\mathrm{~ns}$ \\
\hline & $\mathrm{C}(\mathrm{CG})$ & $\mathrm{ns}$ & & ns & ns & $\mathrm{L}^{* *}$ & & $\mathrm{~ns}$ & $\mathrm{~ns}$ & $\mathrm{~L}^{* *}$ & & $\mathrm{~ns}$ & ns & ns & $\mathrm{L}^{*}$ & & $\mathrm{Q}^{\circ}$ \\
\hline & $\mathrm{G}$ & $\mathrm{ns}$ & & ns & $*$ & $\mathrm{~ns}$ & & $\mathrm{~ns}$ & $\mathrm{~ns}$ & $\mathrm{~ns}$ & & $\mathrm{~ns}$ & ns & ns & $\mathrm{ns}$ & & ns \\
\hline & $\mathrm{C} \times \mathrm{G}$ & $* *$ & & ns & $\mathrm{ns}$ & $\mathrm{ns}$ & & $\mathrm{ns}$ & $*$ & $*$ & & $\mathrm{~ns}$ & $*$ & ns & $*$ & & ns \\
\hline \multirow[t]{4}{*}{$0,20-0,40$} & $\mathrm{C}$ (SG) & ns & & $\mathrm{ns}$ & ns & $\mathrm{Q}^{* *}$ & & $\mathrm{~ns}$ & $\mathrm{~L}^{* *}$ & $\mathrm{~L}^{* *}$ & & $\mathrm{~ns}$ & ns & $\mathrm{L}^{\circ}$ & $\mathrm{L}^{* *}$ & & $Q^{*}$ \\
\hline & $\mathrm{C}(\mathrm{CG})$ & ns & & $\mathrm{ns}$ & ns & $\mathrm{L}^{* *}$ & & $\mathrm{Q}^{\circ}$ & $\mathrm{ns}$ & $\mathrm{L}^{* *}$ & & $\mathrm{~ns}$ & $\mathrm{Q}^{*}$ & ns & $\mathrm{L}^{*}$ & & $\mathrm{~L}^{* *}$ \\
\hline & $\mathrm{G}$ & ns & & ns & $*$ & $* *$ & & $\mathrm{~ns}$ & $\mathrm{~ns}$ & $\mathrm{~ns}$ & & ** & $\mathrm{ns}$ & ns & ns & & * \\
\hline & $\mathrm{C} \times \mathrm{G}$ & $\mathrm{ns}$ & & $\mathrm{ns}$ & ns & $\mathrm{ns}$ & & $\mathrm{ns}$ & $\mathrm{ns}$ & $\mathrm{ns}$ & & $*$ & $\mathrm{~ns}$ & ns & $\mathrm{ns}$ & & $* *$ \\
\hline $0,40-0,60$ & C (SG) & ns & & $\mathrm{L}^{*}$ & ns & $\mathrm{Q}^{*}$ & & $\mathrm{~ns}$ & $\mathrm{~L}^{* *}$ & $\mathrm{~L}^{* *}$ & & $\mathrm{~ns}$ & $\mathrm{~ns}$ & $\mathrm{~L}^{* *}$ & $\mathrm{~ns}$ & & $\mathrm{~ns}$ \\
\hline & $\mathrm{C}(\mathrm{CG})$ & ns & & $\mathrm{ns}$ & ns & $\mathrm{L}^{* *}$ & & $\mathrm{~ns}$ & ns & $\mathrm{L}^{* *}$ & & $\mathrm{~ns}$ & $\mathrm{~L}^{* *}$ & $\mathrm{~ns}$ & $\mathrm{~L}^{* *}$ & & $\mathrm{~ns}$ \\
\hline & $\mathrm{G}$ & ns & & $\mathrm{ns}$ & $*$ & * & & $\mathrm{ns}$ & $\mathrm{ns}$ & $\mathrm{ns}$ & & $*$ & $\mathrm{~ns}$ & ns & * & & $* *$ \\
\hline & $\mathrm{C} \times \mathrm{G}$ & $\mathrm{ns}$ & & $\mathrm{ns}$ & $\mathrm{ns}$ & $\mathrm{ns}$ & & $\mathrm{ns}$ & ns & ns & & $\mathrm{ns}$ & $*$ & ns & ns & & $\mathrm{Ns}$ \\
\hline
\end{tabular}

(1) C (SG): efeito das doses de calcário na ausência de gesso, C (CG): efeito das doses de calcário na presença de gesso $\left(2.100 \mathrm{~kg}\right.$ ha $\left.{ }^{-1}\right)$, G: efeito do gesso e C x G efeito da iteração entre calcário e gesso. ${ }^{(2)} \mathrm{L}$ e Q representam efeito linear e quadrático pela regressão polinomial, respectivamente. ns, ${ }^{\circ},{ }^{*} \mathrm{e}{ }^{* *}$ : não-significativo e significativos a 10,5 e $1 \%$ pelo teste t, respectivamente.

íons. O aumento do $\mathrm{pH}$ na superfície do solo pode acelerar a velocidade com que o íon $\mathrm{HCO}_{3}{ }^{-}$, acompanhado por $\mathrm{Ca}$ e $\mathrm{Mg}$, movimenta-se para o subsolo para reagir com a acidez (Caires et al., 2003). De acordo com Rheinheimer et al. (2000), os efeitos da calagem em profundidade somente ocorreram quando o pH (em água), na zona de dissolução do calcário, atingiu valor entre 5,2 e 5,6. Nessa situação, ocorreram a formação e a migração de $\mathrm{Ca}\left(\mathrm{HCO}_{3}\right)_{2} \mathrm{e}$ $\mathrm{Mg}\left(\mathrm{HCO}_{3}\right)_{2}$ para camadas mais profundas do solo. 


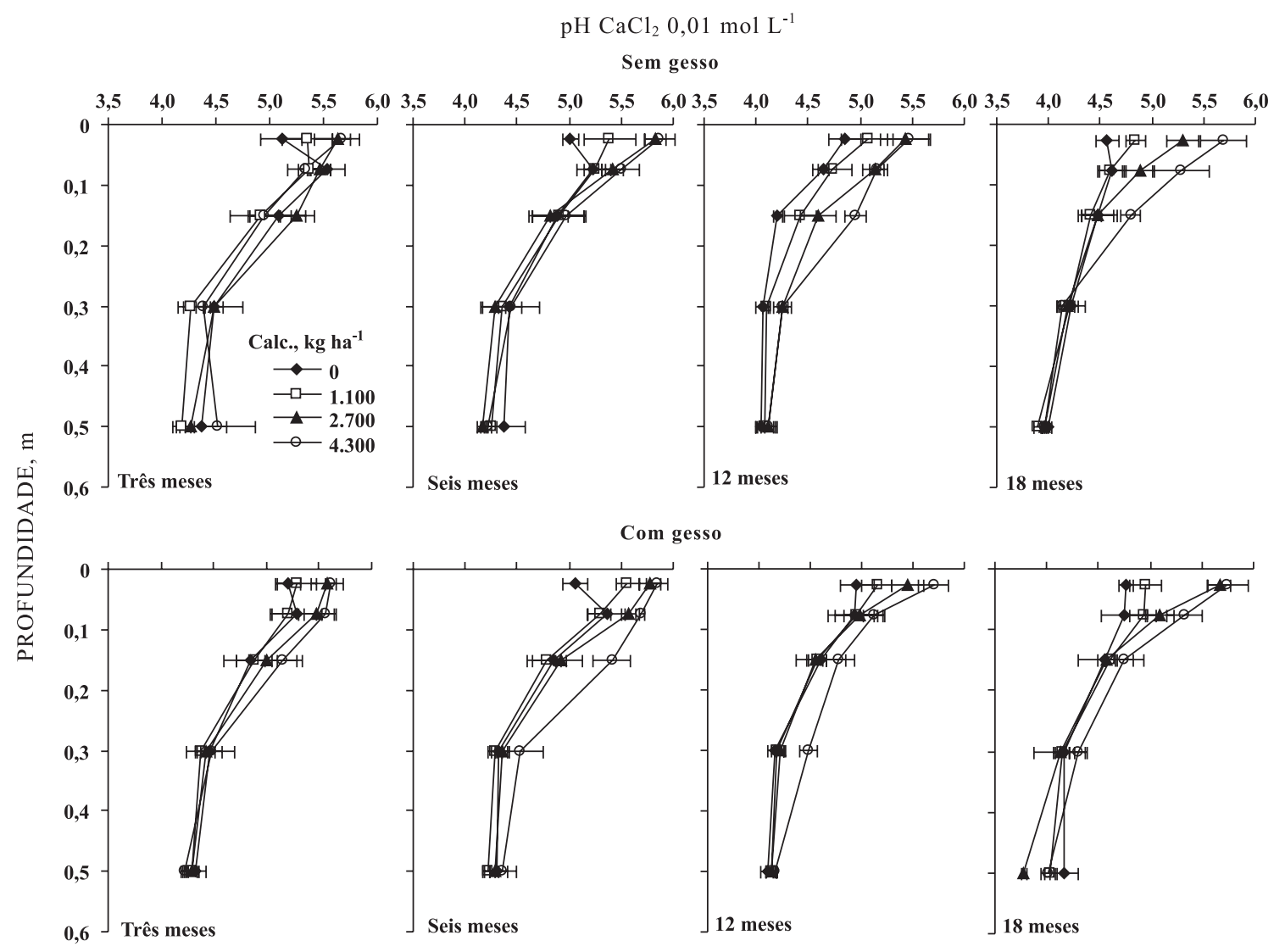

Figura 1. Valores de pH $\left(\mathrm{CaCl}_{2}\right)$ no solo em função da aplicação de doses de calcário, sem e com gesso $\left(2.100 \mathrm{~kg} \mathrm{ha}^{-1}\right)$ em superfície, em quatro épocas de amostragem após a aplicação. As barras horizontais referem-se ao desvio-padrão das médias.

O abundante volume de precipitações que ocorreram, principalmente, nos primeiros seis meses após a aplicação do corretivo, pode ter contribuído para o efeito da calagem aplicada superficialmente na elevação dos valores de $\mathrm{pH}$ até as camadas subsuperficiais do solo. Segundo Myiazawa et al. (2002), o regime hídrico tem grande influência na velocidade de ação do corretivo. Outro fator que pode ter favorecido o efeito do calcário na correção do pH em profundidade, principalmente aos 12 meses após a aplicação, é que essa amostragem foi realizada cerca de dois meses após a colheita da aveia-preta cultivada na área. Trabalhos realizados por Miyazawa et al. (2002) e Bayer \& Amaral (2003), com extratos vegetais, demonstraram que a percolação desses pelo solo contido em colunas aumentou a eficiência da calagem aplicada em superfície, na correção da acidez de camadas subsuperficiais.

Quanto aos efeitos da calagem sobre a elevação do pH do solo, na presença de gesso agrícola, verificou-se que, aos três meses após a adição, eles chegaram a $0,10 \mathrm{~m}$ e aos seis meses, a 0,20 $\mathrm{m}$ de profundidade (Quadro 1 e Figura 1). No entanto, aos 12 meses após a aplicação dos produtos, os efeitos foram observados apenas nas camadas de 0-0,05 e de 0,20-0,40 $\mathrm{m}$ e, aos 18 meses, apenas até a camada de 0,05-0,10 m.
Entretanto, não foi observado efeito isolado da gessagem nos valores de $\mathrm{pH}$.

Verificou-se que, com o passar do tempo, houve diminuição do $\mathrm{pH}$ do solo, porém essa acidificação foi mais evidente nos tratamentos que não receberam calagem (Figura 1). Ciotta et al. (2002) também verificaram acidificação do solo sob plantio direto, especialmente na camada superficial, e atribuíram tal fato principalmente à nitrificação do amônio, proveniente dos fertilizantes de reação ácida que se concentram na superfície do solo, devido ao não revolvimento. Outros autores verificaram que, apesar da diminuição do $\mathrm{pH}$ do solo sob plantio direto, o calcário aplicado em superfície continuou corrigindo a acidez até 19 meses (Lima, 2004) e 48 meses (Rheinheimer et al., 2000) após a aplicação.

Na ausência de gesso agrícola, o calcário promoveu diminuição da acidez potencial do solo $(\mathrm{H}+\mathrm{Al})$ na camada 0-0,05 m, aos três meses, até a camada 0,050,10 e $0,10-0,20 \mathrm{~m}$, aos seis e 12 meses, respectivamente, e apenas até a camada de 0,05$0,10 \mathrm{~m}$ na amostragem realizada aos 18 meses após a aplicação, de forma proporcionalmente inversa à dose aplicada (Quadro 1 e Figura 2). Apesar de o efeito da 
calagem sobre a acidez potencial ter atingido profundidades menores em relação ao $\mathrm{pH}$, os resultados foram coerentes, ou seja, o efeito foi observado em maior profundidade aos 12 meses após a aplicação.

$\mathrm{Na}$ presença de gesso, a calagem proporcionou diminuição dos valores da acidez potencial na camada de $0-0,05 \mathrm{~m}$, aos três meses, e até a camada de 0,05$0,10 \mathrm{~m}$ aos seis meses após a aplicação (Quadro 1 e Figura 2). Porém, aos 12 meses, foi observado efeito nas camadas de $0-0,05$ e $0,10-0,20 \mathrm{~m}$, diminuindo o efeito na camada intermediária. $\mathrm{Na}$ amostragem realizada aos 18 meses, não foi mais observado efeito da calagem e na presença de gesso, sobre os valores de $\mathrm{H}+\mathrm{Al}$ abaixo da camada superficial, comportamento semelhante, porém em ordem inversa ao verificado para o $\mathrm{pH}$. Caires et al. (2000), em um Latossolo Vermelho distrófico textura média, verificaram que a ação máxima da calagem sobre a acidez potencial ocorreu aos 28 meses após a aplicação, principalmente nas camadas superficiais.

Foram pequenos os efeitos da aplicação de gesso na diminuição da acidez potencial, tanto na ausência quanto na presença de calcário. $\mathrm{Na}$ ausência da calagem, houve efeito significativo apenas na camada 0,10-0,20 m, na amostragem realizada aos 12 meses, e na camada de $0,40-0,60 \mathrm{~m}$, na amostragem realizada aos 18 meses (Figura 2 ).
Quanto ao Al trocável, apesar de os teores nas camadas superficiais serem baixos, a aplicação de calcário na ausência de gesso proporcionou diminuição, neutralizando quase totalmente o $\mathrm{Al}$ trocável até a camada de 0,10-0,20 m, efeito verificado na amostragem realizada aos seis meses (Quadro 1 e Figura 3).

$\mathrm{O}$ maior efeito da calagem sobre os teores de $\mathrm{Al}$ trocável foi observado na amostragem realizada aos 12 meses após a aplicação, atuando em todas as profundidades estudadas (Quadro 1 e Figura 3). Os maiores efeitos da calagem em profundidade indicam que, provavelmente, alguma porção do calcário ainda continuava reagindo na superfície do solo. Porém, neste experimento, o efeito da calagem na diminuição do $\mathrm{Al}$ trocável não foi duradouro, e na amostragem de 18 meses foi observada alteração apenas nas camadas de $0-0,05$ e $0,40-0,60 \mathrm{~m}$, não observando os efeitos nas demais profundidades, semelhante ao que ocorreu com os valores de $\mathrm{pH}$. Por outro lado, a diminuição do efeito da calagem sobre os teores de Al trocável na amostragem realizada aos 18 meses em comparação com a de 12 meses, principalmente em profundidade, pode estar relacionada com o tipo de complexo formado com o $\mathrm{Al}^{3+}$. Segundo Miyazawa et al. (1992), o complexo Al-ligante será mais estável quanto maior for o número de ligação do tipo anel com cinco ou seis átomos. Além disso, segundo Bayer \& Amaral (2003), o efeito dos resíduos vegetais na diminuição da acidez

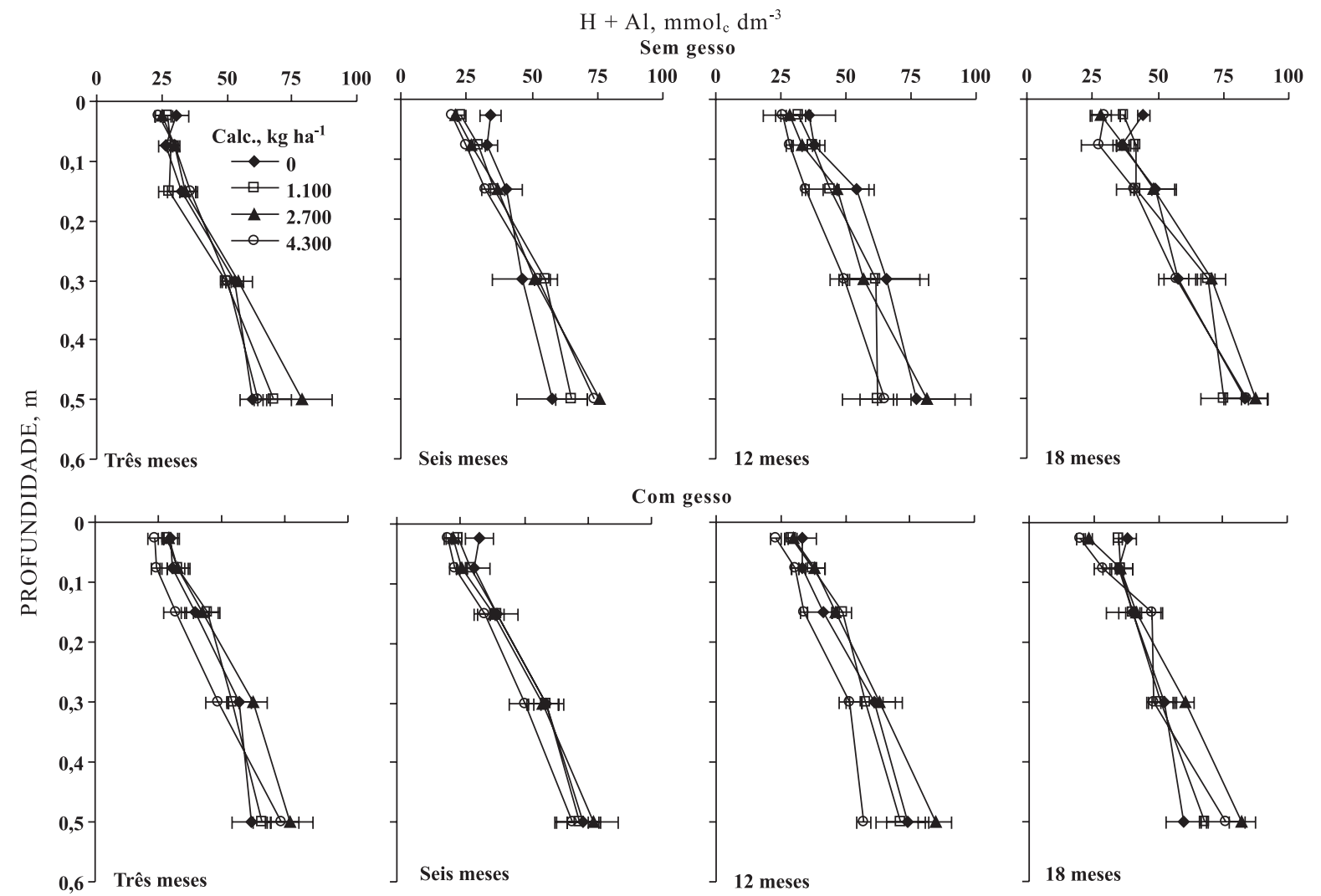

Figura 2. Valores de acidez potencial $(\mathrm{H}+\mathrm{Al})$ no solo em função da aplicação de doses de calcário, sem e com gesso $\left(2.100 \mathrm{~kg} \mathrm{ha}^{-1}\right)$ em superfície, em quatro épocas de amostragem após a aplicação. As barras horizontais referem-se ao desvio-padrão das médias. 


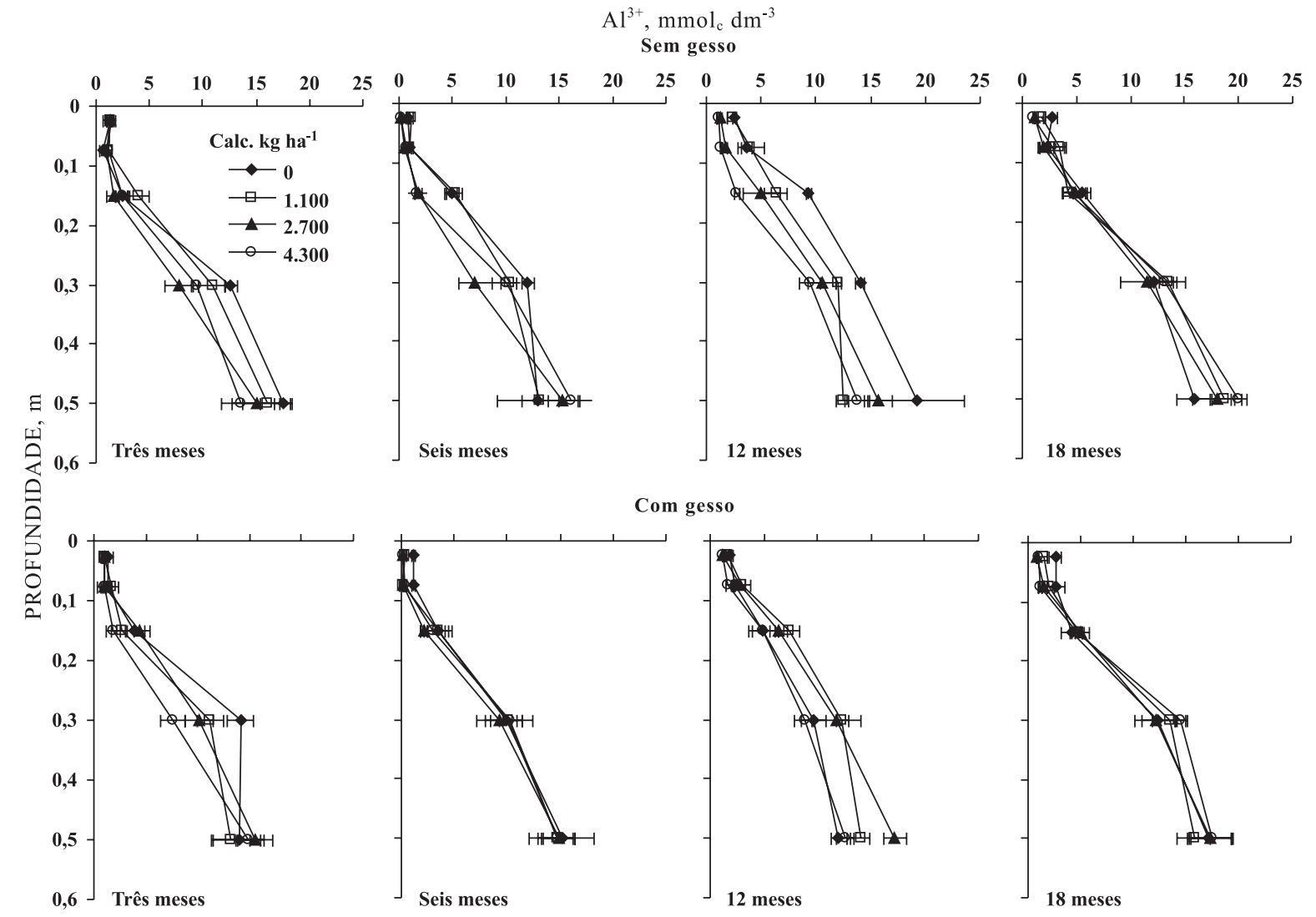

Figura 3. Teores de Al trocável no solo em função da aplicação de doses de calcário, sem e com gesso $\left(2.100 \mathrm{~kg} \mathrm{ha}^{-1}\right)$ em superfície, em quatro épocas de amostragem após a aplicação. As barras horizontais referem-se ao desvio-padrão das médias.

do solo é temporária, pois os ácidos orgânicos podem ser rapidamente transformados pelos microrganismos no solo e adsorvidos nos constituintes do solo, especialmente nos minerais de argila. Nos tratamentos que receberam gesso agrícola, verificase que os maiores efeitos da calagem foram observados nas camadas superficiais do solo, principalmente após a segunda amostragem.

Verificou-se efeito da aplicação superficial de gesso apenas na amostragem realizada aos 12 meses. Na ausência da aplicação de calcário, o gesso havia reduzido os teores de $\mathrm{Al}$ trocável em todas as profundidades (Quadro 1 e Figura 3). Algumas hipóteses têm sido sugeridas para explicar os mecanismos envolvidos na diminuição do Al trocável pela aplicação de gesso. Uma delas seria a liberação de $\mathrm{OH}^{-}$pelo $\mathrm{SO}_{4}{ }^{2-}$, mediante a troca de ligantes, com a formação de estruturas hidroxiladas de $\mathrm{Al}$, mecanismo chamado de "autocalagem" (Reeve \& Sumner, 1972). Poderia também ocorrer precipitação de $\mathrm{Al}$ com a formação de minerais (Adams \& Rawayfih, 1977). Outra possibilidade seria a lixiviação de $\mathrm{Al}$ acompanhando o gesso, o que pode ser, em parte, favorecida pela formação, principalmente, de pares iônicos ou complexos $\mathrm{AlSO}_{4}{ }^{+}$(Pavan et al., 1984).
Essas podem ser explicações para a diminuição do Al trocável pela aplicação de gesso, principalmente nas camadas mais profundas, já que o gesso aumentou os teores de $\mathrm{S}_{-} \mathrm{SO}_{4}{ }^{2-}$ em todo o perfil do solo e, de forma mais acentuada, no subsolo (Figura 4).

A ausência de efeito do gesso na diminuição do $\mathrm{Al}$ trocável, nos tratamentos que receberam calcário, principalmente na amostragem realizada aos 12 meses após a aplicação (Figura 3), deve-se ao acentuado efeito da calagem em todas as profundidades, favorecida, provavelmente, pela ação dos ácidos hidrossolúveis provenientes da cultura da aveia-preta depositados sobre o solo (Miyazawa et al., 2002; Soratto \& Crusciol, 2007). Apesar dos efeitos tanto da calagem quanto da aplicação de gesso agrícola, os teores de $\mathrm{Al}^{3+}$ permaneceram altos em todas as profundidades, a partir da amostragem realizada aos 12 meses.

A calagem influenciou de forma pouco expressiva os teores de sulfato ( $\mathrm{S}_{-} \mathrm{SO}_{4}{ }^{2-}$ ) no perfil do solo. Os maiores efeitos foram observados aos três meses após a aplicação (Quadro 1 e Figura 4), principalmente nas camadas mais profundas. Quaggio et al. (1993) verificaram que, 18 meses após a incorporação de $6 \mathrm{t} \mathrm{ha}^{-1}$ de gesso, praticamente todo o Ca e o S-SO ${ }_{4}^{2-}$ foram lixiviados para profundidades superiores a 
0,60 $\mathrm{m}$, demonstrando efeito residual inferior ao observado neste trabalho, com aplicação de gesso em superfície. Caires et al. (1998), em um Latossolo Vermelho distrófico textura média, verificaram que, 24 meses após a aplicação de uma dose de $12 \mathrm{t} \mathrm{ha}^{-1}$ de gesso em superfície, cerca de $60 \%$ do ${\mathrm{S}-\mathrm{SO}_{4}}^{2-}$ já havia sido lixiviado para camada abaixo de $0,80 \mathrm{~m}$ de profundidade e que apenas uma pequena parte (10\%) encontrava-se na camada de $0-0,20 \mathrm{~m}$.

A pequena retenção do $\mathrm{S}_{-} \mathrm{SO}_{4}{ }^{2-}$ nas camadas superficiais do solo pode ser atribuída aos maiores valores de $\mathrm{pH}$ observados nessas camadas. A elevação do $\mathrm{pH}$ promove a predominância de cargas elétricas negativas, que favorecem a movimentação do $\mathrm{S}_{-} \mathrm{SO}_{4}{ }^{2-}$ (Camargo \& Raij, 1989; Quaggio et al., 1993).

Os teores de Ca trocável foram incrementados principalmente nas camadas superficiais do solo, com o aumento das doses de calcário e também pela aplicação de gesso (Quadro 1 e Figura 5). Diversos trabalhos citam a elevação nos teores de Ca trocável do solo sob influência da aplicação superficial de calcário (Oliveira \& Pavan, 1996; Caires et al., 1999, 2000, 2004; Rheinheimer et al., 2000), ou de gesso (Oliveira \& Pavan, 1996; Caires et al., 1999, 2004). No entanto, grande parte desses trabalhos não apresenta ou comenta efeito algum da interação entre a calagem e a gessagem nos teores de Ca trocável no solo. Como os dois produtos são fontes de Ca, neste trabalho foi possível observar interação entre a calagem e a gessagem, principalmente nas camadas superficiais do solo, evidenciando que tanto o calcário quanto o gesso, aplicados em superfície, contribuíram para a elevação dos teores de Ca em profundidade no solo (Figura 5). Porém, a aplicação combinada de calcário e gesso agrícola promoveu maior elevação nos teores de Ca trocável, principalmente nas camadas superficiais do solo, corroborando os resultados obtidos por Caires et al. $(1998,2003)$.

$\mathrm{Na}$ amostragem realizada aos três meses após a aplicação, observou-se grande elevação nos teores de Ca trocável nas camadas superficiais do solo pela aplicação de calcário e gesso (Figura 5). Porém, com o passar do tempo, houve diminuição nesses teores, principalmente até a amostragem de 12 meses, semelhante ao ocorrido para o $\mathrm{pH}$ (Figura 1), o que pode ser atribuído à elevada extração de Ca pelas culturas do arroz e da aveia-preta. Pöttker \& Ben (1998) e Caires et al. (2000) também verificaram elevação dos teores de Ca trocável, principalmente nas camadas superficiais do solo, com a aplicação de calcário em superfície e posterior diminuição nos teores. No entanto, aos 18 meses após a aplicação, apesar de pequeno, foi possível observar efeito positivo da calagem até a profundidade de $0,60 \mathrm{~m}$, principalmente quando aplicada na presença de gesso.

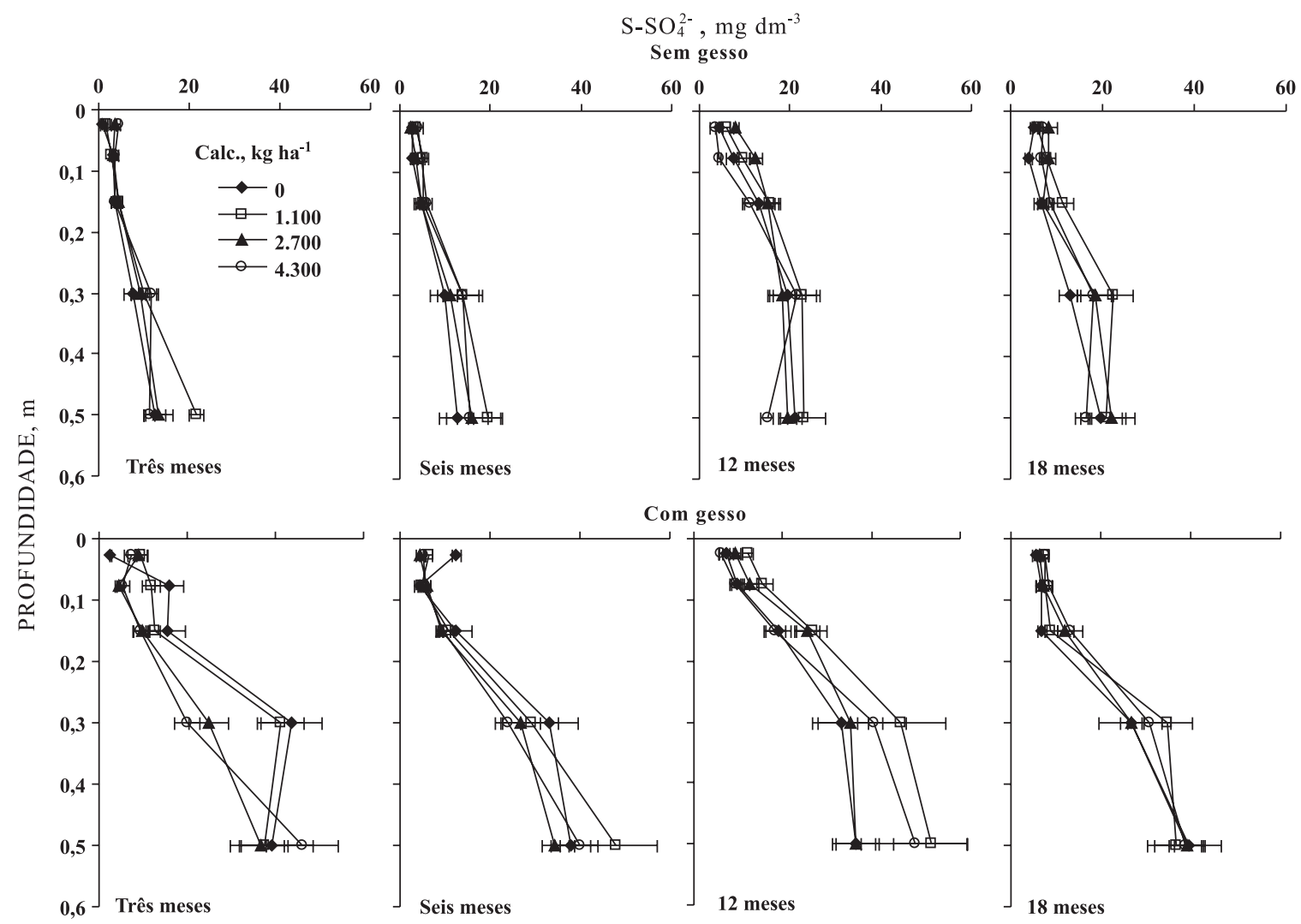

Figura 4. Teores de enxofre ( $\left.\mathrm{S}_{-} \mathrm{SO}_{4}{ }^{-2}\right)$ no solo em função da aplicação de doses de calcário, sem e com gesso $\left(2.100 \mathrm{~kg} \mathrm{ha}^{-1}\right)$ em superfície, em quatro épocas de amostragem após a aplicação. As barras horizontais referem-se ao desvio-padrão das médias. 


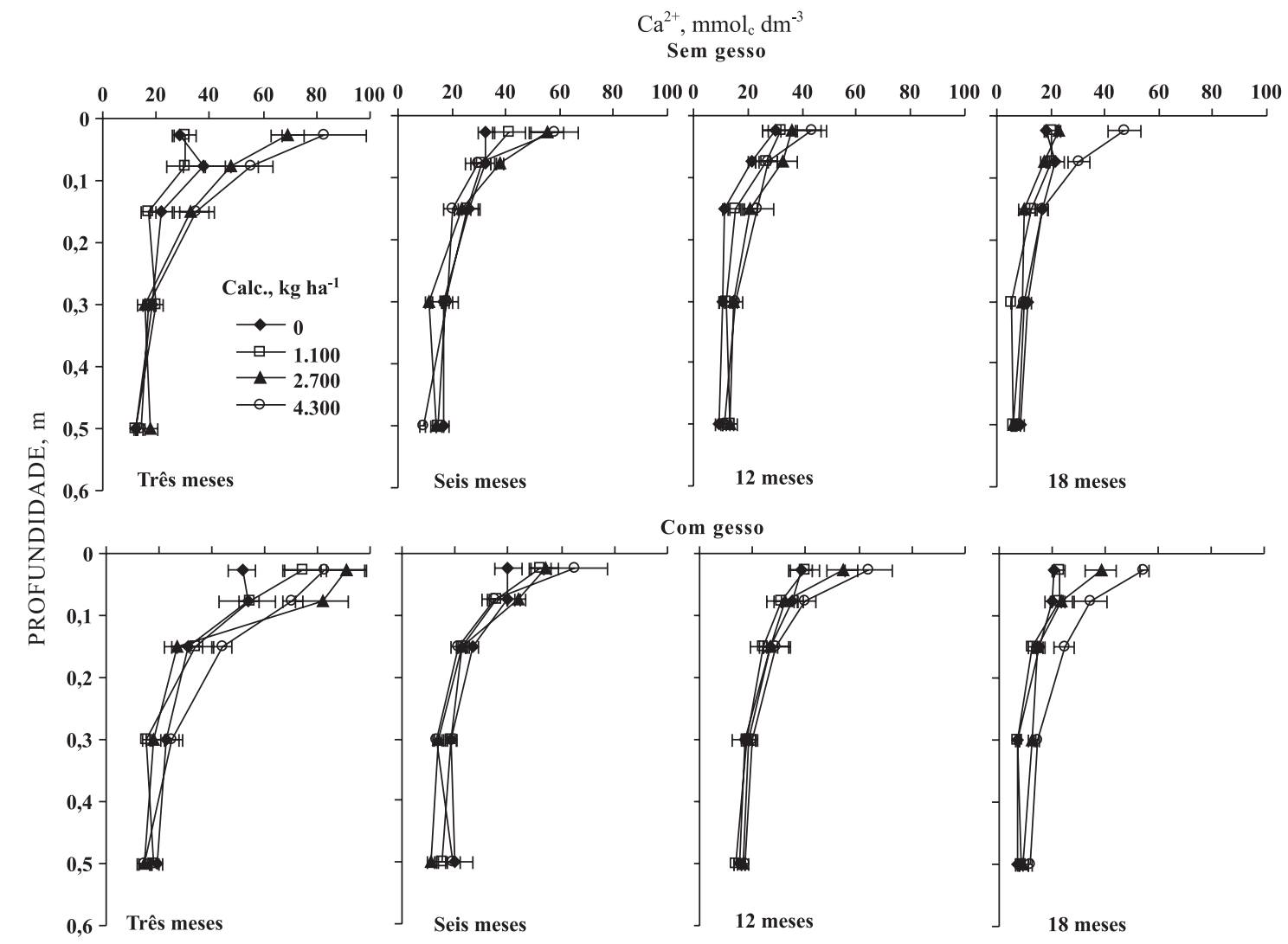

Figura 5. Teores de Ca trocável no solo em função da aplicação de doses de calcário, sem e com gesso $\left(2.100 \mathrm{~kg} \mathrm{ha}^{-1}\right)$ em superfície, em quatro épocas de amostragem após a aplicação. As barras horizontais referem-se ao desvio-padrão das médias.

Nas duas primeiras amostragens (três e seis meses), verificou-se efeito da calagem nos teoeres de $\mathrm{Mg}$ trocável, tanto na presença quanto na ausência de gesso apenas na camada superficial do solo (Quadro 1 e Figura 6). O movimento do $\mathrm{Mg}$ no perfil do solo pode ser explicado pela formação de complexos orgânicos hidrossolúveis a partir de ácidos orgânicos liberados dos restos vegetais presentes na superfície do solo (Miyazawa et al., 1992, 2002). Dessa forma, o fato da terceira amostragem ter sido realizada aproximadamente dois meses após o manejo da cultura da aveia-preta, que foi cultivada na área com a finalidade de produção de grãos, demonstra que os restos dessa cultura podem ter contribuído de forma expressiva para o caminhamento do $\mathrm{Mg}$ no perfil do solo, já que, segundo Miyazawa et al. (2002), esses resíduos são os que têm maior efeito sobre a mobilidade dos produtos da dissolução do calcário no solo.

A aplicação de gesso afetou os teores de Mg trocável no perfil do solo principalmente na ausência da calagem (Figura 6). Aos 12 meses após a aplicação, o gesso promoveu elevação nos teores de Mg trocável na camada de 0,10-0,20 m, nos tratamentos que não receberam calagem. No entanto, aos 18 meses após a aplicação, houve diminuição nos teores de Mg trocável, praticamente em todo o perfil do solo estudado, em função da aplicação de gesso isoladamente. A lixiviação de $\mathrm{Mg}$ tem sido freqüentemente observada nos estudos com aplicação superficial de gesso (Caires et al., 1998, 1999, 2003, 2004).

Neste trabalho, a calagem reduziu as perdas de Mg provocadas pela adição de gesso, apesar de relatos de que, na presença de calcário, a lixiviação de $\mathrm{Mg}$ trocável foi mais intensa (Caires et al., 1998). Uma possível explicação para tal fato seria a maior quantidade de $\mathrm{Ca}$ adicionada ao tratamento que recebeu calagem mais gessagem, o que promoveria sua rápida associação com o íon acompanhante, no caso o $\mathrm{SO}_{4}{ }^{2-}$, tornado-o passível de lixiviação em detrimento da movimentação do $\mathrm{Mg}$.

Quanto à saturação por bases (V), o comportamento foi semelhante ao observado para os teores de Ca e $\mathrm{Mg}$ trocáveis (Quadro 1 e Figura 7). Os maiores efeitos da calagem e da gessagem, nos valores de saturação por bases até a profundidade de 0,60 m, aos 12 meses após a aplicação, foram decorrentes da movimentação de Ca e Mg no perfil do solo, provavelmente proporcionado pelos compostos hidrossolúveis originários dos resíduos, principalmente da aveia-preta cultivada na área (Soratto \& Crusciol, 2007), como já foi discutido anteriormente. 


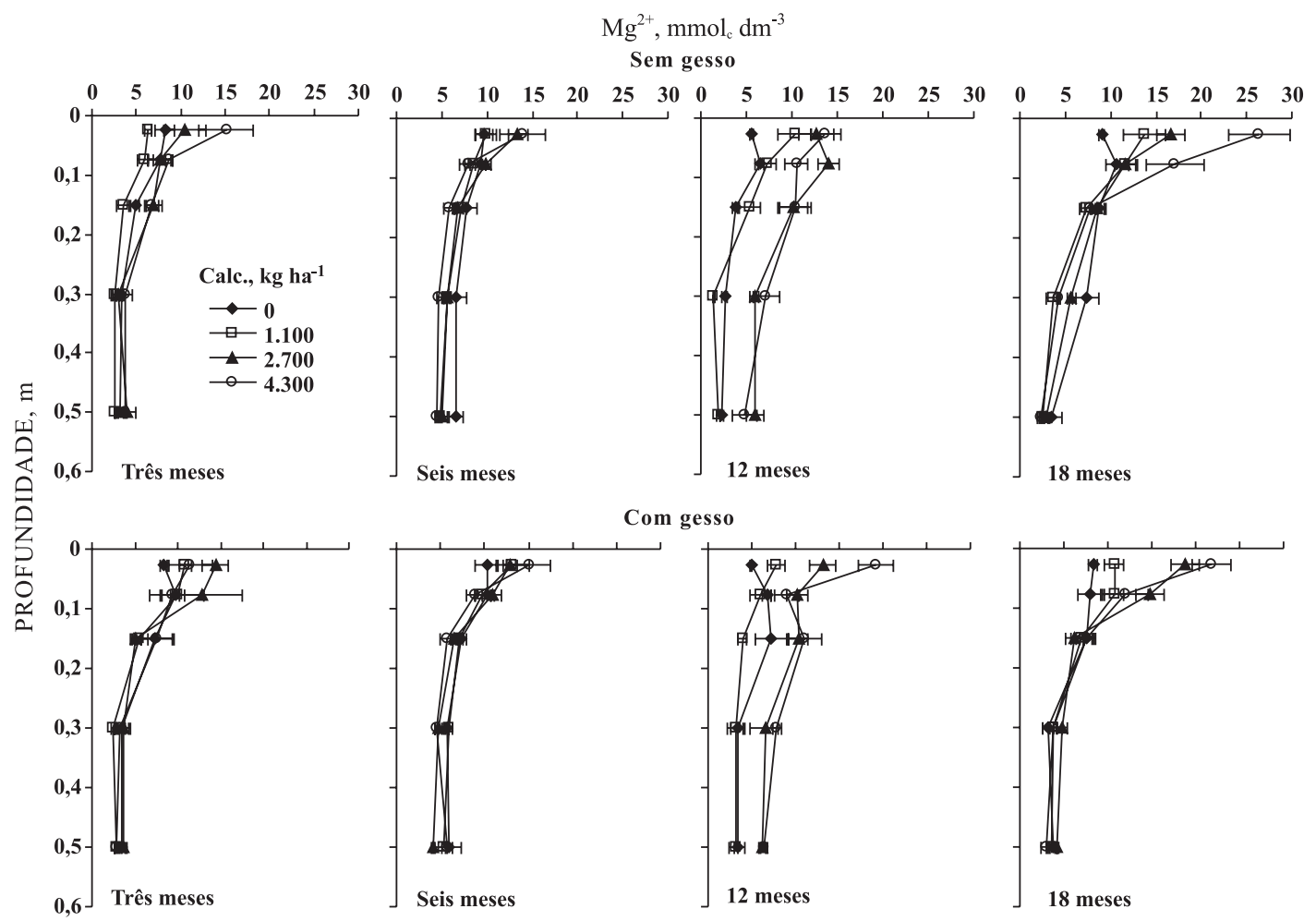

Figura 6. Teores de Mg trocável no solo em função da aplicação de doses de calcário, sem e com gesso $\left(2.100 \mathrm{~kg} \mathrm{ha}^{-1}\right)$ em superfície, em quatro épocas de amostragem após a aplicação. As barras horizontais referem-se ao desvio-padrão das médias.

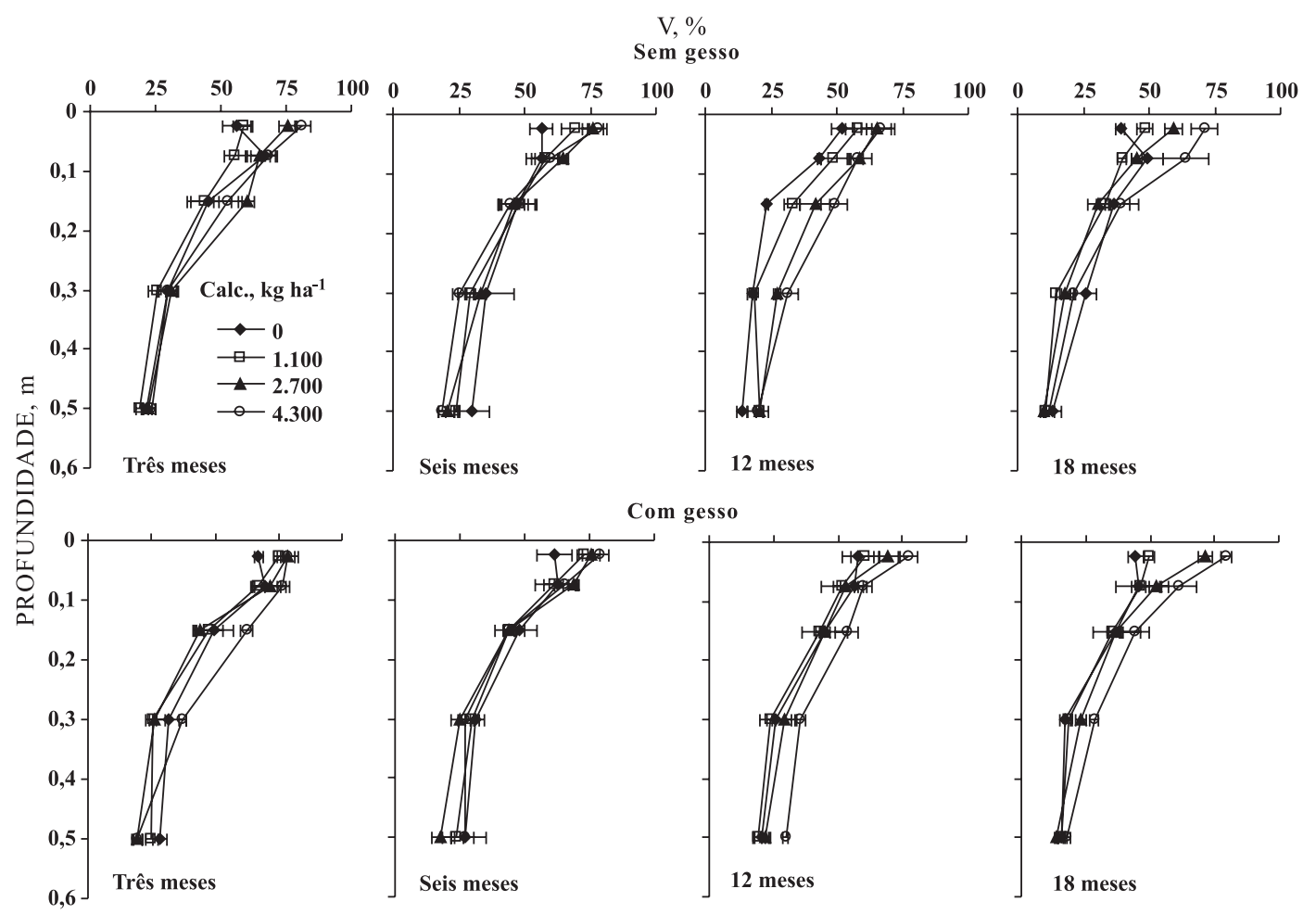

Figura 7. Valores de saturação por bases (V) no solo em função da aplicação de doses de calcário, sem e com gesso $\left(2.100 \mathrm{~kg} \mathrm{ha}^{-1}\right)$ em superfície, em quatro épocas de amostragem após a aplicação. As barras horizontais referem-se ao desvio-padrão das médias. 
Os maiores valores de saturação por bases em função da aplicação de gesso nos tratamentos que não receberam calcário devem-se ao aumento nos teores de Ca também verificados nesses tratamentos (Figura 7). O gesso, além de ser fonte de Ca, promove maior mobilidade desse cátion no solo devido ao íon acompanhante $\mathrm{SO}_{4}^{2-}$ (Dal Bó et al., 1986). Contudo, a maioria dos valores de saturação por bases, nas quatro épocas de amostragem, foi inferior aos estimados. Apenas nos tratamentos em que a dose de calcário foi estimada para elevar a saturação por base a $50 \%$, alguns dos valores obtidos ficaram acima ou próximos dos estimados (Figura 7).

Neste experimento, embora a calagem superficial tenha elevado os valores de $\mathrm{pH}$ na camada de $0-0,20 \mathrm{~m}$ (Quadro 1 e Figura 1), não alterou os teores de $\mathrm{Cu}$, $\mathrm{Fe}, \mathrm{Zn}$ e Mn (Quadro 2). Alleoni et al. (2005) verificaram diminuição dos teores de Fe e Mn nas camadas superficiais do solo mediante a aplicação de calcário em superfície. De acordo com Camargo et al. (1982), foi detectada em solos paulistas correlação negativa entre $\mathrm{pH}$ e os teores de $\mathrm{Zn}, \mathrm{Mn}$ e Fe. Contudo, Camargo et al. (1997), em um Latossolo Vermelho, também não observaram redução nos teores desses nutrientes, mesmo com a incorporação de até 9,0 t ha ${ }^{-1}$ de calcário.

Os teores de Fe e Mn observados neste experimento são semelhantes aos verificados por Camargo et al. (1997) e se encontram na faixa considerada alta por Raij et al. (1996). Quanto ao Zn, os valores encontrados também são semelhantes aos verificados por Camargo et al. (1997), porém, no geral, se situam em uma faixa de teores considerada média a alta (Raij et al., 1996). Com relação ao $\mathrm{Cu}$, os teores verificados no solo deste experimento são considerados elevados (Raij et al., 1996) e bem superiores aos observados por Camargo et al. (1997).

A aplicação de calcário em superfície, em sistema plantio direto recém-implantado em região com inverno seco, tem efeito sobre a correção da acidez e elevação dos teores de $\mathrm{Ca}$ e $\mathrm{Mg}$ do solo, principalmente nas camadas superficiais. A aplicação de gesso pode contribuir para que os efeitos alcancem as camadas do subsolo $(0,20-0,60 \mathrm{~m})$, podendo ser utilizado como produto complementar ao calcário, sendo uma alternativa interessante para a melhoria do ambiente radicular do subsolo enquanto a ação corretiva do calcário ainda não atingiu essa camada. Abordagens semelhantes foram realizadas por Oliveira \& Pavan (1986) e Caires et al. (1998, 1999, 2003), porém trabalhando com maiores doses de gesso.

No entanto, neste trabalho, os maiores efeitos da aplicação de calcário e gesso agrícola em superfície, tanto na correção da acidez quanto na elevação dos teores de cátions em profundidade, foram verificados aos 12 meses após a aplicação, ou seja, em amostragem realizada cerca de dois meses após o manejo da cultura da aveia-preta, indicando que os resíduos dessa cultura podem ter influenciado a mobilidade dos
Quadro 2. Teores de cobre, ferro, manganês e zinco no solo (0-0,20 m), em função da aplicação de doses de calcário em superfície, na ausência de gesso, em quatro épocas de amostragem após a aplicação

\begin{tabular}{|c|c|c|c|c|}
\hline Calcário & $\mathbf{C u}$ & $\mathbf{F e}$ & Mn & $\mathrm{Zn}$ \\
\hline \multirow[t]{2}{*}{$\mathrm{kg} \mathrm{ha}^{-1}$} & \multicolumn{4}{|c|}{$-\mathrm{mg} \mathrm{dm}^{-3}$} \\
\hline & \multicolumn{4}{|c|}{ Três meses } \\
\hline 0 & 5,0 & 32,2 & 21,8 & 1,4 \\
\hline 1.100 & 4,1 & 29,2 & 18,0 & 1,1 \\
\hline 2.700 & 4,4 & 28,0 & 16,3 & 1,4 \\
\hline 4.300 & 3,8 & 31,8 & 19,0 & 0,8 \\
\hline \multirow[t]{2}{*}{ Efeito } & $\mathrm{ns}$ & $\mathrm{ns}$ & $\mathrm{ns}$ & $\mathrm{ns}$ \\
\hline & \multicolumn{4}{|c|}{ Seis meses } \\
\hline 0 & 5,3 & 36,4 & 20,6 & 0,8 \\
\hline 1.100 & 5,1 & 36,2 & 21,4 & 0,9 \\
\hline 2.700 & 5,5 & 36,5 & 20,7 & 1,0 \\
\hline 4.300 & 4,6 & 36,4 & 20,3 & 0,9 \\
\hline \multirow[t]{2}{*}{ Efeito } & $\mathrm{ns}$ & $\mathrm{ns}$ & $\mathrm{ns}$ & $\mathrm{ns}$ \\
\hline & \multicolumn{4}{|c|}{12 meses } \\
\hline 0 & 5,3 & 36,5 & 22,4 & 1,0 \\
\hline 1.100 & 4,9 & 39,7 & 24,2 & 1,2 \\
\hline 2.700 & 5,2 & 30,2 & 24,7 & 1,6 \\
\hline 4.300 & 4,9 & 28,5 & 22,7 & 1,1 \\
\hline \multirow[t]{2}{*}{ Efeito } & $\mathrm{ns}$ & $\mathrm{ns}$ & $\mathrm{ns}$ & $\mathrm{ns}$ \\
\hline & \multicolumn{4}{|c|}{18 meses } \\
\hline 0 & 5,0 & 38,0 & 18,3 & 1,3 \\
\hline 1.100 & 4,2 & 37,4 & 18,5 & 1,4 \\
\hline 2.700 & 4,6 & 35,7 & 18,1 & 1,6 \\
\hline 4.300 & 4,2 & 32,0 & 16,5 & 1,2 \\
\hline Efeito & $\mathrm{ns}$ & $\mathrm{ns}$ & $\mathrm{ns}$ & $\mathrm{ns}$ \\
\hline
\end{tabular}

ns: não significativo a $10 \%$ pelo teste t.

produtos da dissolução do calcário, aplicado em superfície, como já havia sido observado por outros autores (Miyazawa et al., 2002; Bayer \& Amaral, 2003).

\section{CONCLUSÕES}

1. A aplicação de calcário em superfície, na implantação do sistema plantio direto, promoveu diminuição da acidez e elevação dos teores de $\mathrm{Ca}$ e $\mathrm{Mg}$ trocável, principalmente em superfície.

2. A aplicação de gesso agrícola promoveu aumentos nos teores de Ca trocável e $\mathrm{S}_{-} \mathrm{SO}_{4}{ }^{2-}$, e diminuição no teor de Al trocável no solo, contribuindo para que os efeitos da calagem superficial nas características químicas do solo alcançassem, de forma mais rápida, as camadas do subsolo $(0,20-0,60 \mathrm{~m})$. 
3. A saturação por bases na camada de $0-0,20 \mathrm{~m}$ de profundidade não atingiu os valores estimados pelo método da elevação da saturação por bases, principalmente nas maiores doses, mesmo com a aplicação de gesso agrícola.

4. A calagem em superfície não alterou os teores de micronutrientes na camada $0-0,20 \mathrm{~m}$ de profundidade.

\section{AGRADECIMENTO}

À Fapesp, pela concessão de bolsa de doutorado ao primeiro autor.

\section{LITERATURA CITADA}

ADAMS, F. \& RAWAYFIH, Z. Basalumite and alumite: A possible cause of sulfate retention by acid soils. Soil Sci. Soc. Am. J., 41:686-692, 1977.

ALLEONI, L.R.F.; CAMBRI, M.A. \& CAIRES, E.F. Atributos químicos de um Latossolo de cerrado sob plantio direto, de acordo com doses e formas de aplicação de calcário. R. Bras. Ci. Solo, 29:923-934, 2005.

AMADO, T.J.C.; BAYER, C.; ELTZ, F.L.F. \& BRUM, A.C.R. Potencial de plantas de cobertura em acumular carbono e nitrogênio no solo no plantio direto e a melhoria da qualidade ambiental. R. Bras. Ci. Solo, 25:189-197, 2001.

AMARAL, A.S.; ANGHINONI, I.; HENRICHIS, R. \& BERTOL, I. Movimentação de partículas de calcário no perfil de um Cambissolo em plantio direto. R. Bras. Ci. Solo, 28:359367, 2004.

BARIZON, R.R.M. Calagem na superfície para a cultura da soja, em semeadura direta sobre Brachiaria brizantha. Botucatu, Universidade Estadual Paulista, 2001. 88p. (Tese de Mestrado)

BAYER, C. \& AMARAL, A.S. Amenização da acidez de um Latossolo argiloso por extratos aquosos de plantas de cobertura de inverno. R. Ci. Agrovet., 2:88-96, 2003.

CAIRES, E.F.; ALLEONI, L.R.F.; CAMBRI, M.A. \& BARTH, G. Surface application of lime for crop grain production under a no-till system. Agron. J., 97:791-798, 2005.

CAIRES, E.F.; BANZATTO, D.A. \& FONSECA, A.F. Calagem na superfície em sistema plantio direto. R. Bras. Ci. Solo, 24:161-169, 2000.

CAIRES, E.F.; BLUM, J.; BARTH, G.; GARBUIO, F.J. \& KUSMAN, M.T. Alterações químicas do solo e resposta da soja ao calcário e gesso aplicados na implantação do sistema de plantio direto. R. Bras. Ci. Solo, 27:275-286, 2003.

CAIRES, E.F.; CHUEIRI, W.A.; MADRUGA, E.F. \& FIGUEIREDO, A. Alterações de características químicas do solo e resposta da soja ao calcário e gesso aplicados na superfície em sistema de cultivo sem preparo de solo. R. Bras. Ci. Solo, 22:27-34, 1998.
CAIRES, E.F.; FONSECA, A.F.; MENDES, J.; CHUEIRI, W. \& MADRUGA, E.F. Produção de milho, trigo e soja em função das alterações das características químicas do solo pela aplicação de calcário e gesso na superfície, em sistema de plantio direto. R. Bras. Ci. Solo, 23:315-327, 1999.

CAIRES, E.F.; KUSMAN, M.T.; BARTH, G.; GARBUIO, F.J. \& PADILHA, J.M. Alterações químicas do solo e resposta do milho à calagem e aplicação de gesso. R. Bras. Ci. Solo, 28:125-136, 2004.

CAMARGO, O.A. \& RAIJ, B.van. Movimento de gesso em amostras de solo com diferentes propriedades eletroquímicas. R. Bras. Ci. Solo, 13:275-280, 1989.

CAMARGO, O.A.; CASTRO, O.M.; VIEIRA, S.R. \& QUAGGIO, J.A. Alterações de atributos químicos do horizonte superficial de um Latossolo e um Podzólico com a calagem. Sci. Agric., 54:1-8, 1997.

CAMARGO, O.A.; VALADARES, J.M.A.S. \& DECHEN, A.R. Efeitos do $\mathrm{pH}$ e da incubação na extração do manganês, zinco, cobre e ferro do solo. R. Bras. Ci. Solo, 6:83-88, 1982.

CIOTTA, M.N.; BAYER, C.; ERNANI, P.R.; FONTOURA, S.M.V.; ALBUQUERQUE, J.A. \& WOBETO, C. Acidificação de um Latossolo sob plantio direto. R. Bras. Ci. Solo, 26:1055-1064, 2002.

DAL BÓ, M.A.; RIBEIRO, A.C.; COSTA, L.M.; THIÉBAUT, J.T.L. \& NOVAIS, R.F. Efeito da adição de diferentes fontes de cálcio em colunas de solo cultivadas com cana de açúcar. I. Movimentação de bases no solo. R. Bras. Ci. Solo, 10:195-198, 1986.

EMPRESA BRASILEIRA DE PESQUISA AGROPECUÁRIA EMBRAPA. Centro Nacional de Pesquisa de Solos. Manual de métodos de análise de solo. 2.ed. Brasília, 1997. 212p.

EMPRESA BRASILEIRA DE PESQUISA AGROPECUÁRIA EMBRAPA. Centro Nacional de Pesquisa de Solos. Sistema brasileiro de classificação dos solos. Brasília, 2006. 412p.

HERNANI, L.C.; KURIHARA, C.H. \& SILVA, W.M. Sistema de manejo do solo e perdas de nutrientes e matéria orgânica por erosão. R. Bras. Ci. Solo, 23:145-154, 1999.

LIMA, E.V. Plantas de cobertura e calagem superficial na fase de implantação do sistema de plantio direto em região de inverno seco. Botucatu, Universidade Estadual Paulista, 2004. 125p. (Tese de Doutorado)

MELLO, J.C.A.; VILLAS BÔAS, R.L.; LIMA, E.V.; CRUSCIOL, C.A.C. \& BÜLL, L.T. Alterações nos atributos químicos de um Latossolo Distroférrico decorrentes da granulometria e doses de calcário em sistemas plantio direto e convencional. R. Bras. Ci. Solo, 27:553-561, 2003.

MIYAZAWA, M.; CHIERICE, G.O. \& PAVAN, M.A. Amenização da toxicidade de alumínio as raízes do trigo pela complexação com ácidos orgânicos. R. Bras. Ci. Solo, 16:209-215, 1992. 
MIYAZAWA, M.; PAVAN, M.A. \& FRANCHINI, J.C. Evaluation of plant residues on the mobility os surface applied lime. Braz. Arch. Biol. Technol., 45:251-256, 2002.

OLIVEIRA, E.L. \& PAVAN, M.A. Control of soil acidity in notillage system for soybean production. Soil Till. Res., 38:47$57,1996$.

PAVAN, M.A.; BINGHAM, F.T. \& PRATT, P.F. Redistribution of exchangeable calcium, magnesium, and aluminum following lime and gypsum applications to a Brazilian Oxisol. Soil Sci. Soc. Am. J., 48:33-38, 1984.

PÖTTKER, D. \& BEN, J.R. Calagem para uma rotação de culturas no plantio direto. R. Bras. Ci. Solo, 22:675-684, 1998.

QUAGGIO, J.A. Acidez e calagem em solos tropicais. Campinas, Instituto Agronômico, 2000. 111p.

QUAGGIO, J.A.; RAIJ, B.van; GALLO, P.B. \& MASCARENHAS, H.A.A. Resposta da soja à aplicação de calcário e gesso e lixiviação de íons no perfil do solo. Pesq. Agropec. Bras., 28:375-383, 1993.

RAIJ, B. van; CANTARELA, H.; QUAGGIO, J.A. \& FURLANI, A.M.C. Recomendações de adubação e calagem para o Estado de São Paulo. 2.ed. Campinas, Instituto Agronômico, 1996. 285p. (Boletim Técnico, 100)
RAIJ, B.van; ANDRADE, J.C.; CANTARELLA, H. \& QUAGGIO, J.A. Análise química para avaliação da fertilidade de solos tropicais. Campinas, Instituto Agronômico, 2001. 284p.

REEVE, N.G. \& SUMNER, M.E. Amelioration of subsoil acidity in Natal Oxisols by leaching of surface-applied amedments. Agrochemophysica, 4:1-6, 1972.

RHEINHEIMER, D.S.; SANTOS, E.J.S.; KAMINSKI, J.; BORTOLUZZI, E.C. \& GATIBONI, L.C. Alterações de atributos do solo pela calagem superficial e incorporada a partir de pastagem natural. R. Bras. Ci. Solo, 24:797-805, 2000 .

SORATTO, R.P. \& CRUSCIOL, C.A.C. Cátions hidrossolúveis na parte aérea de culturas anuais mediante aplicação de calcário e gesso em superfície. R. Bras. Ci. Solo, 31:81-90, 2007.

STONE, L.F. \& SILVEIRA, P.M. Efeitos de sistemas de preparo na compactação do solo, disponibilidade hídrica e comportamento do feijoeiro. Pesq. Agropec. Bras., 34:8391, 1999 .

VITTI, G.C. Enxofre no solo. In: SIMPOSIO SOBRE INTERPRETAÇÃO DE ANÁLISE QUÍMICA DE SOLO E PLANTA PARA FINS DE ADUBAÇÃO, 1., Botucatu, 1988. Anais. Botucatu, FCA-UNESP/FEPAF/ANDA/ POTAFOS, 1988. 39p. 